\title{
Genetic Resources - a new attempt at serving the community
}

\author{
Lorenzo Maggioni $^{*, a}$, Michele Bozzano ${ }^{\mathrm{b}}$, Coralie Danchin ${ }^{\mathrm{c}}$ and Sandra Goritschnig ${ }^{\mathrm{a}}$ \\ ${ }^{a}$ European Cooperative Programme for Plant Genetic Resources (ECPGR), Bioversity International, Maccarese, Italy \\ ${ }^{b}$ European Forest Genetic Resources Programme (EUFORGEN), European Forest Institute (EFI), Barcelona, Spain \\ ${ }^{c}$ European Regional Focal Point for Animal Genetic Resources (ERFP), Institut de l'Elevage (IDELE), Paris, France
}

\begin{abstract}
Through the Horizon 2020 project 'GenRes Bridge' the new journal Genetic Resources was conceived to serve as a new cross-cutting platform for stakeholders and practitioners in genetic resources. Its ambition is to provide access to relevant information and tools for the monitoring, conservation, management, characterization and use of genetic resources, and thus to contribute to the FAO global plans of action on genetic resources. Conceived to fill the gaps left by the discontinuation of the journals Plant Genetic Resources Newsletter and Animal Genetic Resources, it aims at serving the genetic resources community worldwide and across sectors.
\end{abstract}

Keywords: GenRes Bridge, Plant Gentic Resources Newsletter, Animal Genetic Resources, ECPGR, ERFP, EUFORGEN

Citation: Maggioni, L., Bozzano, M., Danchin, C., Goritschnig, S. (2020). Genetic Resources - a new attempt at serving the community. Genetic Resources 1 (1), 1-3. doi: 10.46265/genresj.2020.1.1-3.

(C) Copyright 2020 the Authors.

This is an open access article distributed under the terms of the Creative Commons Attribution License (CC BY 4.0), which permits unrestricted use, distribution, and reproduction in any medium, provided the original author and source are credited.

\section{History}

Between 1970 and 2009, FAO and IPGRI/Bioversity International were jointly producing the Plant Genetic Resources Newsletter $(P G R N)^{1}$, a peer reviewed journal focusing on "genetic resources of useful plants, resulting from new work, historical study, review and criticism in genetic diversity, ethnobotanical and ecogeographical surveying, herbarium studies, collecting, characterization and evaluation, documentation, conservation, and genebank practice". Paper issues were originally distributed free of charge and eventually the publication was converted into an online open access publication. This magazine covered a specific niche of interest for the plant genetic resources community, publishing information that normally would not be suitable for existing scientific journals. It was open to contributions from all regions and offered a free of charge publication service.

\footnotetext{
*Corresponding author: L Maggioni (1.maggioni@cgiar.org)

${ }^{1}$ Plant Genetic Resources Newsletter archive: https://www.bioversityin ternational.org/e-library/library-services/plant-genetic-resources-new sletter/
}

The FAO journal Animal Genetic Resources ${ }^{2}$, supporting the implementation of the global plan of action for animal genetic resources (GPA-AnGR, (FAO, 2007), had a similar history and was discontinued in 2016. Over a 30-year period, more than 600 papers were published and available in 3 languages (English, French and Spanish). The papers published between 2010 and 2016 are freely available online. A majority of the articles were focused on the ruminant species and about $60 \%$ of them were related to the characterization and monitoring of animal genetic resources.

The discontinuation of PGRN and Animal Genetic Resources was determined by strategy changes and redefinition of priorities of the international organizations that were managing these journals.

In the field of plant genetic resources, at least two peer-reviewed magazines (Genetic Resources and Crop Evolution and Plant Genetic Resources: Characterization and Utilization) were already in operation at the time of PGRN and continue today to offer the opportunity to

\footnotetext{
${ }^{2}$ Animal Genetic Resources archive: https://www.cambridge.org/core /journals/animal-genetic-resources-resources-genetiques-animales-re cursos-geneticos-animales
} 
publish scientific contributions. However, the possibility was lost to formally publish 'grey literature' type of contributions, i.e. methods, strategies, guidelines, reports, case studies, etc., with the support of an international institution as a publisher, offering free of charge services. In fact, since the termination of PGRN, the Secretariat of the European Cooperative Programme for Plant Genetic Resources (ECPGR) received various inputs from its members, inquiring about the possibility to resurrect the journal and soliciting action.

As for the field of AnGR, several journals are offering the possibility of publishing work related to animal genetic resources, provided that their scientific interest and scientific quality is in scope with the magazines' objectives, however none of them are specifically dedicated to AnGR. In Europe, an alternative was sometimes found through oral or poster presentations during scientific conferences in Europe, such as the European Federation of Animal Science (EAAP) conference. The annual conference of the EAAP organizes a specific session devoted to AnGR every year, coordinated by ERFP, FAO and EAAP.

\section{A new attempt}

The opportunity to attempt the re-establishment of a journal that would take on the heritage of PGRN and Animal Genetic Resources in a new context was provided by the decision of the three European networks on plant (ECPGR), animal (European Regional Focal Point for Animal Genetic Resources, ERFP) and forest (European Forest Genetic Resources Programme, EUFORGEN) genetic resources to join forces within the Horizon 2020 project 'GenRes Bridge - Joining forces for GenRes and biodiversity management ${ }^{3}$, which was approved for funding by the European Commission (EC) for the period 2019-2021.

As part of this project a task dedicated to the creation of the journal Genetic Resources was included, thus securing funding for the journal's initial establishment and the production of the first three issues. It is the intention of the three networks to develop a sustainability plan for the continuation of the journal after the end of the project, depending on its success and the feedback received from users, thereby exploring the possibility in the future to share costs and responsibilities as part of their own budgets, as well as seeking support from other possible sponsors.

Prior to the launch of the journal, a survey was carried out of selected audiences about the main gaps that a journal on genetic resources would be expected to fill (Maggioni, 2019). The survey gave an indication of an existing interest for a new journal on genetic resources (91\% of respondents). Although agricultural plants $(80 \%)$, including wild relatives (59\%) raised the highest interest, the forestry (24\%) and farm animals (9\%) domains also registered a significant interest, considering that only a limited number of stakeholders from these domains were included among the survey recipients.

The journal was started under the management of the ECPGR Secretariat and is published by Bioversity International on behalf of the ECPGR. The editorial board includes members of the plant and animal genetic resources community with expertise in different sectors of relevance. The journal's focus is on publishing original research as well as methods, strategies, guidelines, case studies or reviews on topics of interest on the present and future use of genetic resources, thus serving a variety of stakeholders across sectors.

Genetic Resources uses the open-source web publishing platform Open Journal Systems (OJS ${ }^{4}$ ), and a webbased production software (www.typeset.io), which guarantee that running costs of the publication are limited, allowing the journal to provide real open access publications, which are free to publish and free to read. The journal is a member of Crossref ${ }^{5}$, a not-for-profit cooperative effort among publishers to enable persistent cross-publisher citation linking in online academic journals. It also adheres to publication ethics as published by the Committee on Publication Ethics (COPE) ${ }^{6}$.

The active support of voluntary reviewers recruited worldwide and particularly within the European networks ensures timely processing of manuscript submissions. The European networks also offer hubs of expertise to support the editorial and language review of articles.

Based in Europe and mainly supported by the European networks, Genetic Resources is open to worldwide contributions, offering a public free of charge service also to other regions. This new journal can thus be seen as a contribution of the European region to the implementation of the FAO global plans of action on genetic resources (FAO, 2011, 2014, 2007), particularly in terms of promoting access to communication, data and information exchange.

The importance of genetic resources, the challenges ahead (primarily habitat destruction and climate change) and the existing gaps of knowledge call for intensified actions and global collaboration, as illustrated in the keynote review by the Commission for Genetic Resources for Food and Agriculture (CGRFA) in this first issue (Pilling et al, 2020).

This journal has the aspiration to contribute to encouraging a fertile framework of collaboration and exchange of information. It is hoped that the opportunity to use the publication services of Genetic Resources, starting with this issue, will be increasingly used and appreciated by contributors and readers. Their feedback will be taken into account and their judgement will eventually determine whether this enterprise deserves to grow and to continue into the future.

\footnotetext{
4 https://pkp.sfu.ca/ojs/

5 www.crossref.org

6 https://publicationethics.org/
}

\footnotetext{
3 www.genresbridge.eu
} 


\section{Acknowledgements}

The Authors acknowledge funding received from the European Union's Horizon 2020 research and innovation programme under grant agreement No 817580 .

\section{References}

FAO (2007). The Global Plan of Action for Animal Genetic Resources and the Interlaken Declaration. url: http://www.fao.org/3/a-a1404e.pdf.

FAO (2011). Second Global Plan of Action for Plant Genetic Resources for Food and Agriculture. url: http://www.fao.org/3/i2624e/i2624e00.pdf.

FAO (2014). Global Plan of Action for the Conservation, Sustainable Use and Development of Forest Genetic Resources. url: http://www.fao.org/3/a-i3849e.pdf.

Maggioni, L. (2019). Survey on gaps to be filled by a new journal. url: https://www.genresj.org/index. php/grj/GenResBridge_survey.

Pilling, D., Belanger, J., Diulgheroff, S., Koskela, J., Leroy, G., Mair, G., and Hoffmann, I. (2020). Global status of genetic resources for food and agriculture: challenges and research needs. Genetic Resources 1(1), 4-16. doi: 10.46265/genresj.2020.1.4-16 